\title{
Prehypertension in Adolescent Children
}

\author{
Sunil Natha Mhaske ${ }^{1^{*}}$ and Sharadini Dahanukar ${ }^{2}$ \\ ${ }^{1}$ Department of Paediatrics, Dr. Vithalrao Vikhe Patil Foundation's Medical College and Hospital, Ahmednagar, Maharashtra, India \\ ${ }^{2}$ Consultant Geriatric Services and Parkinson's Disease Support Group, Pune, India
}

\begin{abstract}
Hypertension in adolescent children was very much ignored and not considered a major issue in the past but fortunately in the recent years, it has gradually become a source of concern especially as children are known to maintain and the predictor of their blood pressures into adulthood. In the year 2004, National High Blood Pressure Education Program Working Group on High Blood Pressure in Children and Adolescents recommended a new designation of pre-hypertension for children with mildly elevated blood pressure. Epidemiological transition with increasing prevalence of Cardiac risk factors is evident in adults as well as in children. The foundations of Raised blood pressure in the adult are laid in child age and in adolescence period. The phenomenon of tracking or follow up of blood pressure directs that children and adolescents are in a raised blood pressure category tend to all in the same category when they become adults. Early diagnosis and management of prehypertension and hypertension in children and adolescent population will help in reducing the prevalence of prehypertension and hypertension with its complications in the nearby future adult population.
\end{abstract}

Keywords: Adolescents $•$ Blood pressure $\bullet$ Cardiovascular disease $\bullet$ Hypertension $\bullet$ Pre-hypertension

\section{Introduction}

Globally raised blood pressure population is an important public health problem because of its association with more chances of cardiovascular diseases. It is one of the leading causes of morbidity and mortality worldwide and accounted for 9.4 million deaths and 7\% of DALYs (Disability Adjusted Life Years) in 2010. In 2000, around one billion of adult world population had hypertension and by 2025, this is expected to increase to two billion. In India, hypertension is the leading Non Communicable Disease with risk of nearly $10 \%$ of all deaths. [1]

Recently childhood hypertension has reached epidemic problem worldwide which is largely associated with the increase prevalence of childhood obesity [2]. Hypertension once was considered rare because of under diagnosis and lack of awareness in children and adolescents which has now become a major public health challenge as it increases the risk of coronary artery calcifications, ventricular hypertrophy and increased carotid intima media thickness. High blood pressure is the strongest indicator of adult blood pressure [2].

India is undergoing a fast epidemiological transition; the problem of chronic diseases is over taking the burden of infectious diseases. According to world health report, 2002, in India, cardiovascular diseases will be major cause of morbidity and mortality by 2020. In 2020, 2.6 million, Indians are predicted to die due to coronary artery disease and nearly half of deaths are likely to occur in young and middle aged individuals. In short, Hypertension is the main leading cause of global disease burden [3].

Hypertension, at present becoming a source of growing concern in children in developing countries. Therefore, measurement of blood pressure and early detection of prehypertension and hypertension is essential to minimize complications later in life [4]. Hypertension is one of the ten frequently occurred common chronic diseases in childhood which predisposes children to adult hypertension [5].

Adolescence (10-19 years) is an important period of growth and maturation of children. During this time period most of the mental and physical changes occurs to which continues till adulthood. It is a most important developmental phase (transition period) in the life of adolescents from childhood to adulthood. Here children start to make their individual choices and develop personal life styles. Unfortunately, most of the lifestyle patterns adopted by adolescent children are really a dangerous to their physical and mental health also to wellbeing. Nearly two- third of premature death and one- third of disease burden are associated with conditions or behaviors that began in adolescence including diet pattern, exercise, tobacco and alcohol use. Most of these behaviors and risk factors are preventable as well as modifiable if proper lifestyle modification is done. Early phase of adolescence childhood is the proper time for these interventions [1]. The foundations of hypertension in an adult life are laid in childhood and adolescence. There is a tendency for blood pressure to gradually increase with age [6].

Identification of the precursors of cardiac diseases in childhood is the very important milestone because the risk for cardiac disease starts at low levels of blood pressure. The National High Blood Pressure Education Program Working Group on High Blood Pressure in Children and Adolescents (Working Group-2004) with recent updated recommendations for the evaluation of elevated blood pressure in adults created a new designation of "Prehypertension" to identify children and adolescents for future risk of developing hypertension. Hypertension and prehypertension are welldefined, prevalent, asymptomatic, chronic conditions in children and adolescents $[7,8]$.

The Fourth Report described "Prehypertension" as an indication for lifestyle modification and also recommended blood pressure monitoring

"Address for Correspondence: Sunil Natha Mhaske, Department of Paediatrics, Dr. Vithalrao Vikhe Patil Foundation's Medical College and Hospital, Ahmednagar, Maharashtra, India, Tel: 8554990221; E-mail: sunilmhaske1970@gmail.com

Copyright: $\odot 2020$ Mhaske SN, et al. This is an open-access article distributed under the terms of the creative commons attribution license which permits unrestricted use, distribution and reproduction in any medium, provided the original author and source are credited.

Received: 09 November, 2019; Accepted: 24 January, 2020; Published: 31 January, 2020 
approximately every 6 months. No recommendation was made on repeated measurement of blood pressure to verify the designation of prehypertension [9].

As per American medical classification, Prehypertension (high normal blood pressure or borderline hypertension) is increased blood pressure is above normal but not up to the level of to be considered as hypertension. Prehypertension is an early warning for possible changes that could lead to cardiac and renal diseases [10].

Prehypertension requires more careful attention and is a single significant risk factor for future development of hypertension in adolescents. Overweight and obesity are important contributing factors for adolescent prehypertension. Hypertension associated with obesity in childhood is largely preventable [11].
The trends of increasing prevalence of prehypertension and hypertension in urban as well as rural population alerts for a joint effort targeted at recognizing asymptomatic hypertension and prehypertension in children and adolescents. Earlier is the age of onset of untreated hypertension there will be more reduction in life expectancy [10]. Indian children are more susceptible for obesity mediated hypertension which is one of the modifiable risk factor for childhood hypertension.

\section{Prevalence of Pre-Hypertension}

Table 1. Pre-Hypertension in Adolescents: Risk and Progression [8].

\begin{tabular}{|c|c|c|c|c|c|}
\hline No. & Study & Place & Year & Prehypertension & Hypertension \\
\hline 1 & Working Group report & & & $12-17 \%$ & \\
\hline 2 & Salma Shaziya and Soumya M & Madikeri, Karnataka & 2015 & $16.13 \%$ & \\
\hline 3 & Zhaoyang Fan ID et al. & Beijing, China & 2019 & $6.0 \%$ & $10.6 \%$ \\
\hline 4 & Roya Kelishadia and Ramin Heshmatb & Isfahan, Iran & 2013 & $6.9 \%$ & $5.6 \%$ \\
\hline 5 & $\begin{array}{l}\text { Riley, Margaret, Anita K Hernandez, and } \\
\text { Angela L Kuznia [14] }\end{array}$ & Ann Arbor, Michigan & 2012 & $3.4 \%$ & $3.6 \%$ \\
\hline \multirow[t]{2}{*}{6} & \multirow{2}{*}{$\begin{array}{l}\text { Ujunwa, Fortune A, Anthony N Ikefuna, Ada } \\
\text { RC Nwokocha, and Josephat M Chinawa [10] }\end{array}$} & Enugu, & 2013 & $17.3 \%$ & $5.4 \%$ \\
\hline & & Nigeria & & & \\
\hline 7 & F. Odey et al. & Calabar, Nigeria & 2003 & $7.5 \%$ & $6.7 \%$ \\
\hline 8 & Ostrowska-Nawarycz et al. & Poland & 2007 & $11.1 \%$ & \\
\hline 9 & McNiece et al. & USA & 2007 & $9.5 \%$ & \\
\hline 10 & $\begin{array}{l}\text { Tony, Lawrence, Binu Areekal, AT Surendran } \\
\text { Nair, and R Ramachandran, et al. [6] }\end{array}$ & Kerala, India & 2016 & $21.3 \%$ & $21.4 \%$ \\
\hline 11 & $\begin{array}{l}\text { Patel, Ashish, Anil Bharani, Meenakshi } \\
\text { Sharma, and Anuradha Bhagwat, et al. [16] }\end{array}$ & Indore, M.P & 2019 & $6.5 \%$ & $6.8 \%$ \\
\hline 12 & Sharma et al. & Shimla & & $12.3 \%$ & $5.9 \%$ \\
\hline 13 & Vedavathy S. Sangamesh & Bangalore, India & 2016 & $3.6 \%$ & \\
\hline 14 & Maryam Rafraf & Tabriz, Iran & 2010 & $13.9 \%$ & $19.4 \%$ \\
\hline 15 & Juarez-Rojas et al. & Mexican & 2008 & $10 \%$ & $10.6 \%$ \\
\hline 16 & Moore et al. & America. & 2009 & $16.7 \%$ & $13.8 \%$ \\
\hline 17 & Rajendra Bhimma et al. & KwaZulu-Natal, South Africa & 2018 & $29.7 \%$ & $13.7 \%$ \\
\hline 18 & Chukwunonso ECC Ejike et al. & Nigeria & 2009 & $22.2 \%$ & $17.5 \%$ \\
\hline
\end{tabular}

\section{Definitions of prehypertension}

The Fourth Report of the Task Force on Blood Pressure Control in Children commissioned by the National Heart, Lung and Blood Institute
(NHLBI)-When a child's average blood pressure exceeds the 90th percentile but is less than 95th percentile for age, sex and height (Tables 1 and 2) [4]. 
The World Health Organization classifies prehypertension as a blood pressure reading that measures between $120 / 80$ and $139 / 89[11,12]$.

Table 2. Blood pressure reading.

\begin{tabular}{lll}
\hline Classification & JNC $7(\mathrm{mmHg})$ & 2004 Working Group (Percentile for age, height and gender) \\
\hline Normotensive & $<120 / 80$ & $<90$ th \\
\hline Pre-hypertensive & $120-139 / 80-89$ & 90 th $-<95$ th or if BP $\geq 120 / 80 \mathrm{mmHg}$ even if $<90$ th \\
\hline Stage 1 & $140-159 / 90-99$ & 95 th-99th $+5 \mathrm{mmHg}$ (at 3 separate visits) \\
\hline Stage 2 & $\geq 160 / 100$ & $>99$ th $+5 \mathrm{mmHg}$ (at 3 separate visits)
\end{tabular}

\section{Causes of pre-hypertension and hypertension}

Primary hypertension: No underlying cause.

History of hypertension in any family member.

Overweight or obesity.

Common in infants.
Secondary hypertension: Known underlying medical cause (Table 3).

$80 \%$ of children have kidney disease or blood vessel abnormalities.

$5 \%$ have an endocrinological disorder.

2 to $5 \%$ have heart disease.

Common in Children and adolescents $[13,14]$.

Table 3. Risk factors for Prehypertension [11-15].

\begin{tabular}{ll}
\hline Overweight and obesity & Medicines-Steroids or OC pills \\
\hline Stress & Premature birth or low birth weight \\
\hline Lack of exercise & Family history of hypertension \\
\hline Too much salt in the diet & Long term breastfeeding reduces risk of hypertension. \\
\hline Use of alcohol, tobacco or illegal drugs & Maternal smoking during pregnancy \\
\hline Male sex & Eating high sodium foods \\
\hline Black Childers & No clear genetic pattern. \\
\hline Sedentary lifestyle & Children born to hypertensive parents \\
\hline Poor diet habits & Disorders of sleep- Obstructive sleep apnea, primary snoring, sleep fragmentation \\
\hline
\end{tabular}

\section{Clinical features}

Most of the times Prehypertension is asymptomatic at the time of diagnosis (Table 4).

Table 4. Prehypertension symptoms $[11,13]$.

\begin{tabular}{ll}
\hline Headaches & Chest pain \\
\hline Loss of vision & Abdominal pain \\
\hline Double-vision & Breathing problems \\
\hline Fatigue & Dizziness \\
\hline
\end{tabular}

\section{Measurement of Blood Pressure}

Quiet and comfortably sitting child with back supported and feet are touching to the ground for five minutes.
Measurement of Blood pressure to be done in the right arm well supported at the level of heart.

Blood pressure cuff having inflatable bladder width of 40 percent and length of 80 to 100 percent of the arm circumference.

Blood pressure cuff is tied point midway between acromion and olecranon of arm circumference. 
Measurements should be taken to the nearest $2 \mathrm{mmHg}$.

First, fourth and fifth Korotkoff sound phases to be noted.

First and fourth Korotkoff sounds are taken as the systolic and diastolic pressures respectively as recommended by the 4th Report on the diagnosis, evaluation and treatment of high blood pressure in children and adolescents.

If blood pressure reading is more than 90th percentile, measurement should be repeated to confirm validity in same visit.

To diagnose as a prehypertension or hypertension, Blood pressure readings should be elevated on three separate occasions [14] (Figures 1-4).

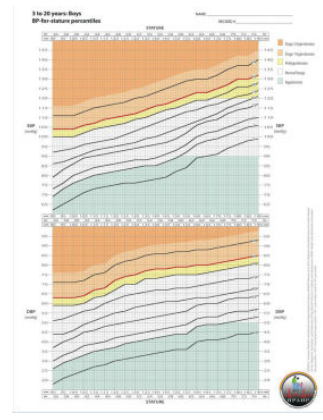

Figure 1. Percentile charts for Boys.

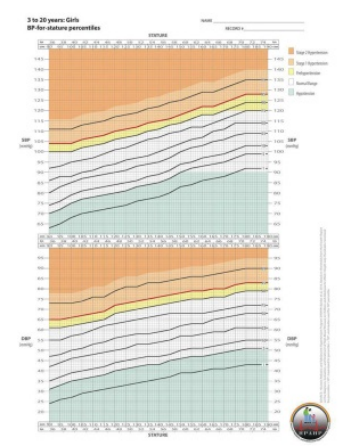

Figure 2. Percentile charts for Girls [15-17].

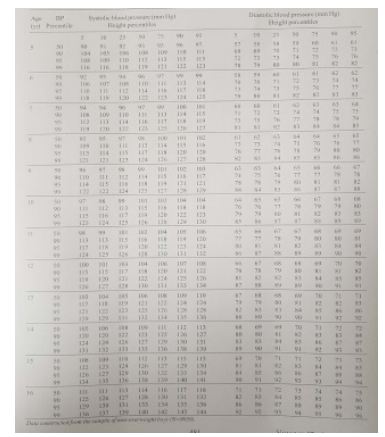

Figure 3. Blood pressure for adolescent Boy (Age and Height Percentile).

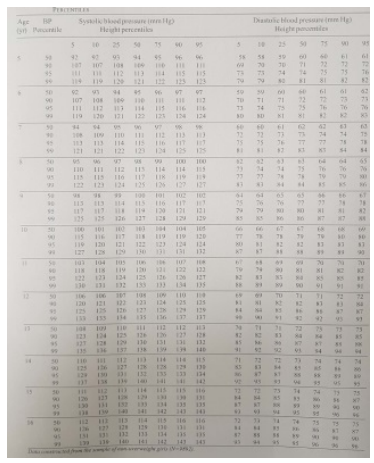

Figure 4. Blood Pressure Levels for adolescent Girl (Age and Height Percentile).

\section{Risk for Progression of Prehypertension to Hypertension}

An adolescent who is having blood pressure readings normal at initial screening develops hypertension at a rate of $0.3 \%$ per year where as the incidence rate with pre-hypertension is $1.1 \%$ per year. These develop hypertension by $6.6 \%$ per year [8].

\section{Biomarkers Related Prehypertension}

Biomarkers are defined as an objective and quantifiable characteristics of biological processes which can be measured accurately and reproducible again [18].

\section{Biomarkers in pathogenesis and diagnosis of hypertension}

Vascular dysfunction- Angiotensin A and vasoconstriction inhibiting factor (VIF) (Tables 5-7).

Table 5. Inflammation and oxidative stress.

Interleukin-6 (IL-6)

P-selectin
Intracellular adhesion molecule 1 (ICAM1)

Tumor necrosis factor- $\alpha$ (TNF- $\alpha$ )

Table 6. Biomarkers that predict development of hypertension.

Fibrinogen Increased uric acid




\begin{tabular}{ll}
\hline Rennin & High levels of CRP \\
\hline Aldosterone & Increased levels of plasminogen activator inhibitor-1 (pai-1) \\
\hline Vitamin d3 & Urinary albumin excretion (UAE) \\
\hline Homocysteine & B-type natriuretic peptide \\
\hline Aldosterone level, & N-terminal pro-atrial natriuretic peptide \\
\hline
\end{tabular}

Table 7. Biomarkers in disease progression.

Biomarkers of target organ damage due to hypertension

\begin{tabular}{lll}
\hline CRP & PAI-1 & OX-LDL \\
\hline Leptin & TNF ALPHA & ADMA \\
\hline SDMA & EH & \\
\hline
\end{tabular}

Biomarker in control of HTN- There is an increase in CD45+ and CXCR2+ cells in the aorta (Tables 8-11).
Table 8. Cardiac damage.

\begin{tabular}{ll}
\hline Microalbuminuria & BNP \\
\hline Galectin 3 (gal-3) & Cardiac troponins \\
\hline
\end{tabular}

Markers of collagen turnover

Table 9. Vascular damage.

\begin{tabular}{ll}
\hline E-selectin & Plasma vascular endothelial growth factor (plasma VEGF) \\
\hline Fibrinogen & Serum cystatin-C concentration
\end{tabular}

Table 10. Renal damage.

\begin{tabular}{lll}
\hline Serum creatinine & GFR & UAE \\
\hline Adrenomedullin & Vanil mandellic acid (VMA) & Metanephrin \\
\hline
\end{tabular}

Table 11. Cerebral damage.

Ubiquitin C-terminal hydrolase-L1 (UCH-L1) levels

Enolase (NSE) are promising future biomarkers

\section{Treatment}

\section{Diet}

DASH diet- Dietary Approaches to Stop Hypertension.

A low-sodium and high potassium diet.

More fruits in diet [11].

Non-starchy vegetables lke beans, green leafy vegetables, cucumbers, carrots and tomatoes [19].

Use of Whole grains.

Limit diet with Tran's fatty acid.

Low proportion of refined carbohydrates like sugar, white flour and corn syrup in diet [20].

Drink plenty of water.

Eat Potassium rich fruits like papaya, banana, dark leafy greens, sweet potato, prune juice, tomato juice, avocado, oranges, yogurt, milk, dried beans and black beans, chickpeas, lentils, fish, beef, pork, nuts and seeds such as flax, pistachio, pumpkin, almonds and sunflower seeds [21].
Avoid junk foods.

\section{Lifestyle modification}

Reaching and maintaining a healthy weight [12].

Regular exercise for 30 minutes of moderate exercise such as brisk walking [22].

Stress control.

\section{Medications}

Use of thiazide diuretics, Angiotensin-converting enzyme inhibitors, calcium channel blockers and angiotensin receptor blockers are effective and safe also well tolerated by children and adolescents [14].

Beta blockers are not used as first line treatment in children [17].

Drug therapy with antihypertensive in Children should be with lowest recommended dosage and titrated up periodically every two to four weeks till the decided blood pressure is achieved [22] (Table 12).

Table 12. SBP reduction range.

\begin{tabular}{lll}
\hline No. & Modification & SBP reduction (range) \\
\hline 1 & Weight reduction & $5-20 \mathrm{~mm} \mathrm{Hg} / 10 \mathrm{~kg}$ \\
\hline 2 & Adopt DASH eating plan & $8-14 \mathrm{~mm} \mathrm{Hg}$ \\
\hline 3 & Dietary sodium reduction & $2-8 \mathrm{~mm} \mathrm{Hg}$ \\
\hline 4 & Physical activity & $4-9 \mathrm{~mm} \mathrm{Hg}$
\end{tabular}




\section{5}

Smoking cessation

$2-4 \mathrm{~mm} \mathrm{Hg}$

\section{Prevention of Pre Hypertension}

Keep normal weight as per height.

Daily Exercise for about an hour.

Take healthy and nutritious diet.

Don't take alcohol, tobacco products, or illegal drugs [15].

Keep stress levels low, practice relaxation and breathing exercises.

Don't take extra salt in food.

Avoid fast food and junk foods.

Checking of blood pressure and monitoring of weight regularly [23-25].

\section{Prognosis}

Prehypertension increases the chances of heart attacks, congestive heart failure, strokes and kidney failure. Prehypertensive adolescents are three times more prone to have a heart attack compared to a person with normal blood pressure [11].

\section{Conclusion}

The following conclusions can be drawn from the above study:

Raised blood pressure in children and adolescents is a growing health problem which is mostly overlooked. Children and adolescents should be screened for elevated blood pressure annually from the age of three years or at every visit if risk factors are presents.

Periodic screening and monitoring of blood pressure of adolescents should be incorporated into the school health Programme, also general public health education on hypertension and its associated risk factors should be strengthened.

The fourth report on the diagnosis, evaluation, and treatment of high blood pressure in children and adolescents emphasized that all children of 3 years should be doing their blood pressure measurement regularly by every six months.

Education regarding the prevalence of prehypertension and hypertension in Paediatrics population would be useful for policy makers, in order to highlight the significance of training health professionals about integrating blood pressure measurement and tracking in healthy children, and to increase the public awareness about the importance of prevention and control of Pre hypertension from early life.

It is suggested that blood pressure measurement should be done during routine checkup and visit with adolescents whenever they attend clinics.

Health care providers should be sensitized about the situation and made capable of providing preventive measures and guidance on the issue of Prehypertension and hypertension in children.

Circulating biomarkers will be the future of primordial prevention, better control and decrease in death and disability related to Prehypertension and hypertension in children.

Always keep in mind that blood pressure in childhood is the best independent predictor for future Pre hypertension and hypertension in adult life.

\section{References}

1. Amma, Geethadevi Madhavikutty, Bindhu Vasudevan, and Sobha Akshayakumar. "Prevalence and determinants of prehypertension and hypertension among adolescents: a school based study in a rural area of Kerala, India." Int J Res Med Sci3 (2015): 58-64.
2. Dong, Yanhui, Yi Song, Zhiyong Zou, and Jun Ma, et al. "Updates to pediatric hypertension guidelines: influence on classification of high blood pressure in children and adolescents." J Hypertens 37 (2019): 297-306.

3. Koebnick, Corinna, Mary H Black, Jun Wu, and Mayra P Martinez, et al. "The prevalence of primary pediatric prehypertension and hypertension in a real world managed care system." J Clin Hypertens (Greenwich) 15 (2013): 784-792.

4. Okpokowuruk, Frances Sam, Mkpouto Udeme Akpan, and Enobong Emmanuel Ikpeme. "Prevalence of hypertension and prehypertension among children and adolescents in a semi-urban area of Uyo Metropolis, Nigeria." Pan Afr Med J 28 (2017): 303.

5. https://medicalxpress.com/news/2016-11-hypertension-prehypertensionunderdiagnosed-undertreated-children.html

6. Tony, Lawrence, Binu Areekal, AT Surendran Nair, and R Ramachandran, et al. "Prevalence of hypertension and pre-hypertension among adolescent school children in Thiruvananthapuram, Kerala, India." Int J Community Med Public Health 312 (2016): 79-81.

7. Hansen, Matthew L, Paul W Gunn, and David C Kaelber. "Underdiagnosis of hypertension in children and adolescents." JAMA 298 (2007): 874-879.

8. Redwine, Karen M, and Stephen R Daniels. "Prehypertension in adolescents: risk and progression." J Clin Hypertens 14 (2012): 360-364.

9. Falkner, Bonita. "Prehypertension in adolescents: how high is the risk for hypertension?" The Journal of pediatrics 160 (2012): 7-9.

10. Ujunwa, Fortune A, Anthony N Ikefuna, Ada RC Nwokocha, and Josephat M Chinawa. "Hypertension and prehypertension among adolescents in secondary schools in Enugu, South East Nigeria." Italian Journal of Pediatrics 39 (2013): 70.

11. https://en.wikipedia.org/wiki/Prehypertension

12. https://www.getqardio.com/healthy-heart-blog/prehypertension/

13. http://www.childrenshospital.org/conditions-and-treatments/

14. Riley, Margaret, Anita K Hernandez, and Angela L Kuznia. "High Blood Pressure in Children and Adolescents." American family physician 98 (2018): 486-494.

15. https://kidshealth.org/en/teens/hypertension.html

16. Patel, Ashish, Anil Bharani, Meenakshi Sharma, and Anuradha Bhagwat, et al. "Prevalence of hypertension and prehypertension in schoolchildren from Central India." Annals of Pediatric Cardiology 12 (2019): 90.

17. https://www.aafp.org/afp/2018/1015/p486.pdf

18. Shere, Amar, Olanrewaju Eletta, and Hemant Goyal. "Circulating blood biomarkers in essential hypertension: a literature review." JLPM.

19. Assadi, Farahnak. "Prehypertension: a warning sign of future cardiovascular risk." Int J Prev Med5 (2014): S4.

20. https://www.kidney.org/news/kidneyCare/fall10/Prehypertension

21. https://www.healthychildren.org/English/health-issues/conditions/heart/ Pages/High-Blood-Pressure-in-Children.aspx

22. https://www.health.harvard.edu/heart-health/prehypertension-does-it-reallymatter

23. https://www.news-medical.net/news/20190903/Blood-pressure-in-childrenaffected-by-early-environmental-exposures.aspx

24. Kelishadi, Roya, Ramin Heshmat, Gelayol Ardalan, and Mostafa Qorbani, et al. "First report on simplified diagnostic criteria for pre-hypertension and hypertension in a national sample of adolescents from the Middle East and North Africa: the CASPIAN-III study." Journal de Pediatria 90 (2014): 85-91.

25. Sarganas, Giselle, Angelika Schaffrath Rosario, Claudia Niessner, and Alexander Woll, et al. "Tracking of blood pressure in children and adolescents in germany in the context of risk factors for hypertension." International Journal of Hypertension (2018). 
How to cite this article: Sunil Natha Mhaske and Sharadini Dahanukar. "Prehypertension in Adolescent Children". J Hypertens (Los Angel) 9 (2020). 